\title{
Development and validation of an RNAi screen for ABT-737 sensitizers
}

\author{
Kenneth W Yip' \\ Inki Kim' \\ Jason Garrison' \\ Apple Cortez' \\ Nancy Cheung' \\ Pedro Aza-Blanc' \\ Marina Konopleva ${ }^{2}$ \\ Michael Andreeff ${ }^{3}$ \\ John C Reed' \\ 'Sanford-Burnham Medical \\ Research Institute, La Jolla, CA, \\ USA; ${ }^{2}$ Department of Leukemia, \\ ${ }^{3}$ Department of Stem Cell \\ Transplantation and Cellular Therapy, \\ MD Anderson Cancer Center, \\ Houston, TX, USA
}

This article was published in the following Dove Press journal:

International Journal of High Throughput Screening

17 September 2010

Number of times this article has been viewed

\begin{abstract}
The chemical compound ABT-737 is a nanomolar inhibitor of several antiapoptotic Bcl-2 family members with potential therapeutic efficacy for a variety of cancers. Herein, we describe the development of a complementation-based RNAi assay that can be used to identify mechanisms of ABT-737-resistance. HeLa cells, which were resistant to ABT-737, were optimized for reverse-transfection efficiency and tested for siRNA-mediated silencing. The developed assay utilized HeLa cell reverse-transfection with $10 \mathrm{nM}$ siRNA, followed by $48 \mathrm{~h}$ incubation, ABT-737 or DMSO treatment for $24 \mathrm{~h}$, and cell viability measurement using ATPlite (which measures ATP levels as an indicator of cell viability). As a validation, the kinase subset of the Ambion Silencer Human Druggable Genome siRNA Library V2, which consisted of 865 genes (three siRNA sequences per gene), was screened. Several assay-positive siRNAs were tested and confirmed to sensitize cells to ABT-737. Transfection of cells with siRNAs targeting Bcl-2 family member Mcl-1 also potently sensitized HeLa cells to ABT-737. The current assay thus represents a screen that can be utilized to identify ABT-737-sensitizing siRNAs and correspondingly, potential new targets for drug discovery.
\end{abstract}

Keywords: ABT-737, Bcl-2, apoptosis, RNAi screen, siRNA

\section{Introduction}

Cell death includes such processes as apoptosis, autophagy, and necrosis, with apoptosis being common under nonpathological circumstances. ${ }^{1-4}$ The pathological inhibition of apoptosis is a causative and/or contributing factor in autoimmune disease, and is considered a hallmark of cancer. ${ }^{1,5,6}$ Particularly common in cancer is the dysregulation of the Bcl-2-family of proteins, which function to either inhibit (eg, Bcl-2 (BCL2), $\mathrm{Bcl}_{\mathrm{L}}$ (BCL2L1), Mcl-1 (MCL1), Bcl-B (BCL2L10), Bfl-1 (BCL2A1), and Bcl-W (BCL2L2) in humans) or promote (eg, Bax (BAX), Bak (BAK1), Bim (BCL2L11), and Puma (BBC3)) apoptosis at mitochondria. ${ }^{7-9}$

Bcl-2 was initially cloned in the 1980s from follicular lymphomas, wherein its involvement in a reciprocal translocation results in its overexpression and the inhibition of apoptosis. ${ }^{10-13}$ Changes in gene structure, gene copy number, microRNAs, epigenetics, and post-translational modifications have all since been shown to affect the Bcl-2 family proteins in cancer. ${ }^{7,14-17}$ The over-expression of antiapoptotic $\mathrm{Bcl}-2$-family proteins and under-expression of proapoptotic $\mathrm{Bcl}-2$ family proteins not only contributes to cancer pathogenesis, but also allows malignant cells to resist chemotherapeutic interventions. ${ }^{4,18}$ Accordingly, much attention has focused on inhibiting antiapoptotic Bcl-2 family proteins or mimicking proapoptotic $\mathrm{Bcl}-2$ family members. ${ }^{19-24}$

Sanford-Burnham Medical Research Institute, 1090I North Torrey Pines

Road, La Jolla, CA, USA

$\mathrm{Tel}+\mathrm{I}$ 858-646-3100

$\mathrm{Fax}+\mathrm{I}$ 858-646-3194

Email reedoffice@sanfordburnham.org submit your manuscript | www.dovepress.com

Dovepress

DOI: $10.2147 /$ JHTS.SI 2352 
Synthetic compounds such as ABT-737 (and ABT-263), GX15-070, and HA-14-1, as well as natural products such as (-)-Gossypol and (-)-epigallocatechin gallate (EGCG), bind to a hydrophobic cleft on the surface of antiapoptotic Bcl-2-family proteins, inhibiting their cytoprotective activity. ${ }^{4,1825-28}$ Perhaps the most advanced antiapoptotic Bcl-2 family-targeted compound is ABT-737, a nanomolar inhibitor of $\mathrm{Bcl}-\mathrm{xL}, \mathrm{Bcl}-2$, and $\mathrm{Bcl}-\mathrm{w}$ that has progressed to clinical trials in the form of ABT-263..$^{26,29}$ ABT-737 shows efficacy in various cancer cell lines, primary patientderived cells, and animal models. ${ }^{26,30-33}$ However, several ABT-737-resistant tumor cell lines have been identified, such as A549, NCI-H82, NCI-H196, and OCI-AML3, most likely related to the compound's inability to effectively inhibit the antiapoptotic Bcl-2 family proteins Bcl-B, Mcl1 , or Bfl-1 (A1). ${ }^{26,30,34}$

To identify other genes whose products contribute to ABT-737 resistance, we developed an RNA interference (RNAi) assay using an ABT-737-resistent human tumor cell line. A test screen was performed using the kinase subset (865 genes, three different siRNA sequences per gene) of the Ambion Silencer Human Druggable Genome siRNA Library V2, and several siRNAs were confirmed to sensitize cells to ABT-737. In addition, siRNAs targeting Mcl-1 were highly effective at conferring sensitivity to ABT-737 in this assay, confirming prior results showing that expression of Bcl-2 family members that ABT-737 failed to bind are commonly responsible for resistance to this candidate anticancer drug. ${ }^{30,34}$

\section{Methods and materials Cell culture}

HeLa cells were obtained from ATCC (Manassas, VA) and cultured in Dulbecco's modified Eagle's medium (DMEM; Invitrogen, Carlsbad, CA), with 10\% FBS (Clontech, Mountain View, CA) and penicillin-streptomycin (diluted according to manufacturer's specifications; Invitrogen) at $37^{\circ} \mathrm{C}, 5 \% \mathrm{CO}_{2}$.

Reverse-transfections were performed using Lipofectamine RNAiMAX (RNAiMAX; Invitrogen) with several modifications to the manufacturer's specifications. Briefly, siRNAs ( $1 \mu \mathrm{L} /$ well, $10 \mathrm{nM}$ final) were spotted into white, tissue culture-treated, 384-well plates (Greiner Bio-One, Monroe, NC), followed by $10 \mu \mathrm{L} /$ well of an Opti-MEM (Invitrogen)-RNAiMAX mixture (100:1 ratio of OptiMEM:RNAiMAX). The plates were then centrifuged at $1000 \mathrm{rpm}$ for $1 \mathrm{~min}$ and incubated at room temperature for $15 \mathrm{~min}$. Cells ( $40 \mu \mathrm{L} /$ well, 4000 cells/well) were then dispensed using the ThermoScientific Matrix WellMate bulk dispenser (Thermo Fisher Scientific, Hudson, NH), and the plates incubated at $37^{\circ} \mathrm{C}$.

Cell viability relative to untreated cells was measured using the ATPlite Luminescence ATP Detection System (20 $\mu \mathrm{L} /$ well of a 384-well plate; PerkinElmer, Waltham, MA) and an EnVision Multilabel Plate Reader (PerkinElmer) according to the manufacturer's specifications.

\section{Chemicals}

ABT-737 was synthesized at the MD Anderson Cancer Center as described previously. ${ }^{26} \mathrm{ABT}-737$ was diluted in DMSO and then further diluted in water (0.1\% DMSO final). Cisplatin was purchased from Sigma-Aldrich (St Louis, MO).

\section{Immunofluorescence}

Cells were reverse-transfected in 384-well polystyrene clear bottom plates (Greiner). After $72 \mathrm{~h}$, the cells were washed with phosphate-buffered saline (PBS), fixed in a $3.7 \%$ paraformaldehyde (Sigma-Aldrich)/PBS solution for $15 \mathrm{~min}$, washed with PBS, incubated in a $0.1 \%$ Tween-20/PBS solution for $10 \mathrm{~min}$, incubated in a $0.1 \%$ Tween-20 (Sigma-Aldrich) $/ 3 \%$ skim milk/PBS solution for $2 \mathrm{~h}$, washed with PBS, incubated with mouse anti-GAPDH primary antibody $(0.67 \mu \mathrm{g} / \mathrm{mL}$; Invitrogen) in $0.1 \%$ Tween-20/PBS solution at $4^{\circ} \mathrm{C}$ overnight, washed with PBS, incubated with Rhodamine-labeled anti-mouse secondary antibody $(2.67 \mu \mathrm{g} / \mathrm{mL}$; Invitrogen $)$ in a $0.1 \%$ Tween-20/PBS solution at $4^{\circ} \mathrm{C}$ for $4 \mathrm{~h}$, washed with PBS, and incubated with DAPI ( $100 \mathrm{ng} / \mathrm{mL})$ for $30 \mathrm{~min}$. Imaging and analyses were performed using the Cell Lab IC 100 (Beckman Coulter, Fullerton, CA) and CytoShop software (Beckman Coulter).

\section{High-throughput screening}

HeLa cells (4000 cells/well) were reverse-transfected (using RNAiMAX) with no siRNA (negative control), scrambled control siRNA (siSC; negative control), Mcl-1 siRNA (siMcl-1; positive control), or siRNAs from the kinase subset (865 genes, 3 siRNAs/gene) of the Ambion Silencer Human Druggable Genome siRNA Library V2 (Applied Biosystems, Foster City, CA) (10 nM), and incubated for $48 \mathrm{~h}$. The cells were then treated with $0.1 \%$ DMSO or $1 \mu \mathrm{M}$ ABT-737 (dissolved in $0.1 \% \mathrm{DMSO}$ ) for $24 \mathrm{~h}$, after which cell viability was measured using ATPlite. The ThermoScientific Matrix WellMate bulk dispenser and BioMek FX Laboratory Automation Workstation (Beckman Coulter) were used for liquid dispensing and the EnVision Multilabel Plate Reader was 
used for plate reading. The screen was performed twice, with mean results reported. siRNAs were purchased from Ambion, with Ambion identification numbers shown where relevant.

\section{Q-PCR}

Reverse-transfections were scaled to 12 -well plates. At $48 \mathrm{~h}$ after reverse-transfection, RNA was extracted using the RNeasy Mini Kit (Qiagen, Valencia, CA) and cDNA synthesis was performed using SuperScript III RT (Invitrogen), both according to manufacturer's specifications. SYBR Green quantitative real-time polymerase chain reaction (Q-PCR) (Applied Biosystems) was performed with a Mx3000P (Stratagene, Cedar Creek, TX). The following primers were used:

PPID: GACCCAACACAAATGGTTC, AGTCAG CAATGGTGATCTTC

Mc1-1: AACGGGACTGGCTAGTTAA ACA, CCAGCTCCTACTCCAGCAAC

H A K : A T G C C A A G A T C T A C G C T G C T, TCTCCAATCAGCTCCTCCTC

WN K 2: C C C T T G G T G GA GA A G T C A GA, GACCACATGGGAGTCTGAGG

All samples were analyzed in triplicate, with mean fold change in expression was calculated using the $2^{-\Delta \Delta \mathrm{Ct}}$ method, where $\mathrm{Ct}$ values are normalized to PPID $\mathrm{Ct}$ values and compared to untransfected controls. ${ }^{35}$

\section{Statistical analyses}

Statistical analyses was performed using GraphPad Prism (La Jolla, CA) as indicated.

\section{Results \\ Development of an ABT-737-RNAi complementation screen}

Our first objective was to develop a screen for detecting siRNAs that sensitize cells to ABT-737. HeLa cells were characterized for this screen due to their robust nature and ease of manipulation for high throughput screening (HTS). Previous studies have shown that ABT-737 decreases cell viability in a variety of different cell types at concentrations well below $1 \mu \mathrm{M} .{ }^{26,30}$ However, HeLa cells were found to be resistant to ABT-737 (Figure 1A).

Reverse-transfection efficiency in 384-well plates was then assessed. Several reverse-transfection conditions were tested (data not shown), with the most effective shown in Figure 1. Cells were reverse-transfected with scrambled control siRNAs (siSC) or GAPDH siRNAs (siGAPDH) in 384-well plates, and after a $72 \mathrm{~h}$ incubation, GAPDH protein was immunofluorescently stained (Rhodamine) and imaged using high content screening (HCS) equipment. As shown in Figure 1B, siGAPDH efficiently decreased GAPDH protein expression. GAPDH expression, as determined by Rhodamine fluorescence intensity per cell, was also quantified to further evaluate siRNA-mediated silencing. Mock reverse-transfected HeLa cells and siSC reverse-transfected HeLa cells, whether treated with DMSO $(0.1 \%)$ or ABT-737 ( $1 \mu \mathrm{M}, 0.1 \% \mathrm{DMSO}$ ), did not display a decrease in GAPDH protein expression (Figure 1C). In contrast, siGAPDH significantly decreased GAPDH protein expression $(P<0.05$, ANOVA, $n=3)$. This decrease was similar whether cells were treated with DMSO $(0.1 \%)$ or ABT-737 $(1 \mu \mathrm{M}, 0.1 \%$ DMSO), suggesting that RNAi activity was not affected by ABT-737 and that DMSO would provide for an adequate negative control during HTS.

Finally, to validate positive and negative controls, and screening reproducibility, cells were reverse-transfected with either siSC or Mcl-1 siRNAs (siMcl-1), incubated for $48 \mathrm{~h}$, treated with DMSO (0.1\%) or ABT-737 (1 $\mu \mathrm{M}$, $0.1 \%$ DMSO) for $24 \mathrm{~h}$, and assayed for cell viability using ATPlite (which detects ATP levels as an indicator of cell viability) (Figure 1D). As expected, siSC reversetransfection did not significantly change cell viability. siMcl-1 drastically decreased cell viability in the presence of ABT-737 ( $P<0.05$, ANOVA, $\mathrm{n}=12)$, thus validating it as a positive siRNA control. The Z'-factor between ABT-737-treated siSC and ABT-737-treated siMcl-1 reverse-transfected cells was greater than 0.6 , which is considered "excellent". ${ }^{36}$

In summary, the current assay detected siRNAs that sensitize HeLa cells to ABT-737 using DMSO, siSC, and siMcl-1 as controls, and has been validated for siRNA transfection efficiency, siRNA silencing efficiency, and reproducibility (Figure 1E).

\section{ABT-737-RNAi complementation screening}

The aforementioned assay was used to screen the kinase subset (865 genes, three siRNAs/gene) of the Ambion Silencer Human Druggable Genome siRNA Library V2 twice (to increase accuracy), with mean results reported. As shown in Figure 2, siMcl-1 (positive control) decreased cell viability in the presence of ABT-737 as expected (data points falling below the $y=x$ diagonal line). The 10 genes with the lowest average ABT-737:DMSO cell viability ratio were chosen for further analyses. Twelve additional genes 
A

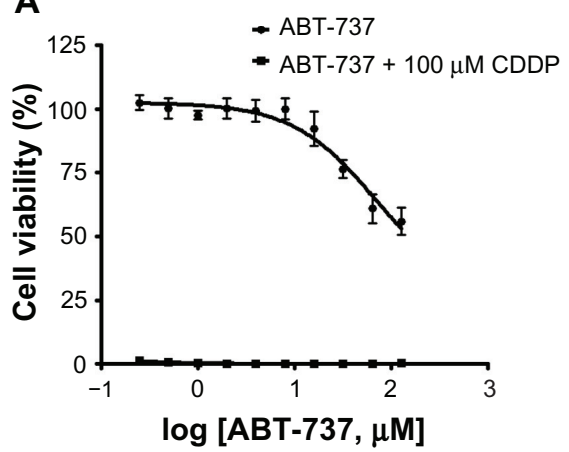

B

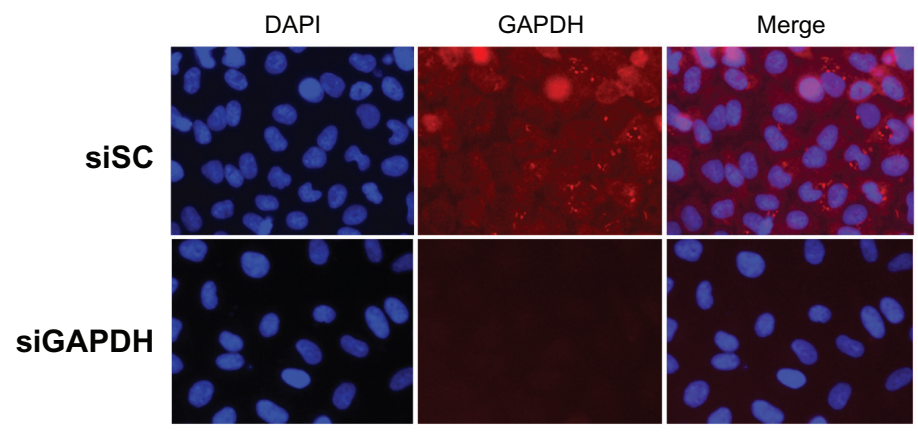

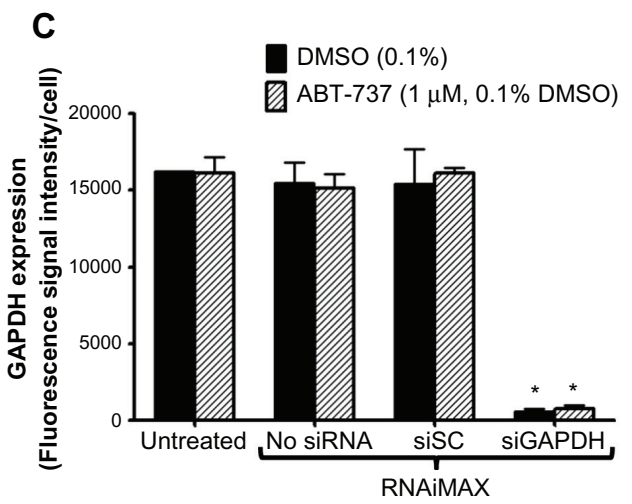

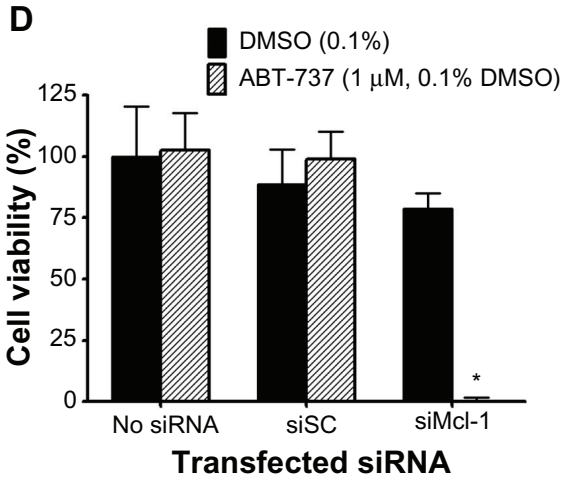

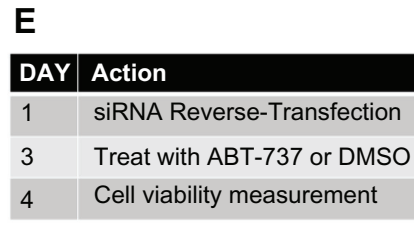

Transfected siRNA

Figure I High-throughput ABT-737-RNAi complementation screen development. A) HeLa cells are resistant to ABT-737. HeLa cells were seeded in 384-well plates (4000 cells/well), incubated overnight, and treated with ABT-737 or ABT-737 + cisplatin (CDDP; $100 \mu$ M; cell death positive control) for 24 h. Cell viability was measured using ATPlite. Mean \pm standard deviation $(n=4)$ are shown. B) Efficient siRNA knockdown of GAPDH expression. HeLa cells (4000 cells/well) were reverse-transfected (using RNAiMAX) with scrambled control siRNA (siSC) or GAPDH siRNA (siGAPDH) in 384-well plates. After $72 \mathrm{~h}$, the cells were fixed, immunofluorescently stained (mouse anti-GAPDH primary antibody $(0.67 \mu \mathrm{g} / \mathrm{mL})$, Rhodamine-labeled anti-mouse secondary antibody $(2.67 \mu \mathrm{g} / \mathrm{mL})$, DAPI (I00 ng/mL)), and imaged using the Cell Lab IC 100. C) Quantification of efficient siRNA transfection and silencing. HeLa cells were reverse-transfected (using RNAiMAX), incubated for $48 \mathrm{~h}$, treated with either $0.1 \%$ DMSO or I $\mu$ M ABT-737 (dissolved in 0.1\% DMSO) for $24 \mathrm{~h}$, immunofluorescently stained for GAPDH, and imaged (six images/well, three wells/condition). Fluorescence signal intensity per cell was quantified using CytoShop software. Mean \pm standard deviation ( $n>200$ cells/condition) are shown, with $*$ indicating $P<0.05$ (ANOVA). D) siMcl-I complements ABT-737. HeLa cells were reverse-transfected, incubated for $48 \mathrm{~h}$, and treated with either DMSO or ABT-737 for $24 \mathrm{~h}$ as previously described. Cell viability was measured using ATPlite. Mean \pm standard deviation are shown, with * indicating $P<0.05$ (ANOVA, $n=12$ ). E) Summary of the developed ABT-737-RNAi complementation screening procedure.

selected based on a combination of having one siRNA with an ABT-737:DMSO cell viability ratio lower than 0.66 and literature searches. siRNAs from a total of 22 genes were thus re-assayed (Table 1). Further genes were not evaluated due to resource limitations.

\section{Further validation of ABT-737-RNAi complementation screening "hits"}

To further validate our top screening "hits", siRNAs for genes with two siRNAs that possessed confirmed ABT-737:DMSO viability ratios of less than 0.66 were purchased and tested. Dose-response studies confirmed siMcl-1-induced sensitization of cells to ABT-737 (Figure 3A). One out of three HAK siRNAs (siHAK) complemented ABT-737, while all WNK2 siRNAs (siWNK2) showed at least some ABT-737 complementation (Figure 3B, 3C).
The siRNAs were then evaluated for efficient target gene expression knockdown relative to untransfected cells by Q-PCR (Table 2). All siRNAs decreased their target RNAs to at least 0.15 -fold levels compared to control. However, siHAK (ID\#111041) induced a 0.34fold change in Mcl-1 and was also the only siHAK to sensitize cells to ABT-737, suggesting that offtarget effects were responsible for the observed siHAK complementation. None of the three WNK2 siRNAs markedly decreased Mcl-1 levels, but interestingly, all three decreased HAK levels. At this time it is not clear whether WNK2 affects HAK, or if off-target siRNA effects were observed. In any case, the results indicate that the current RNAi assay can be effectively used for the high throughput identification of siRNAs that sensitize cells to ABT-737. 


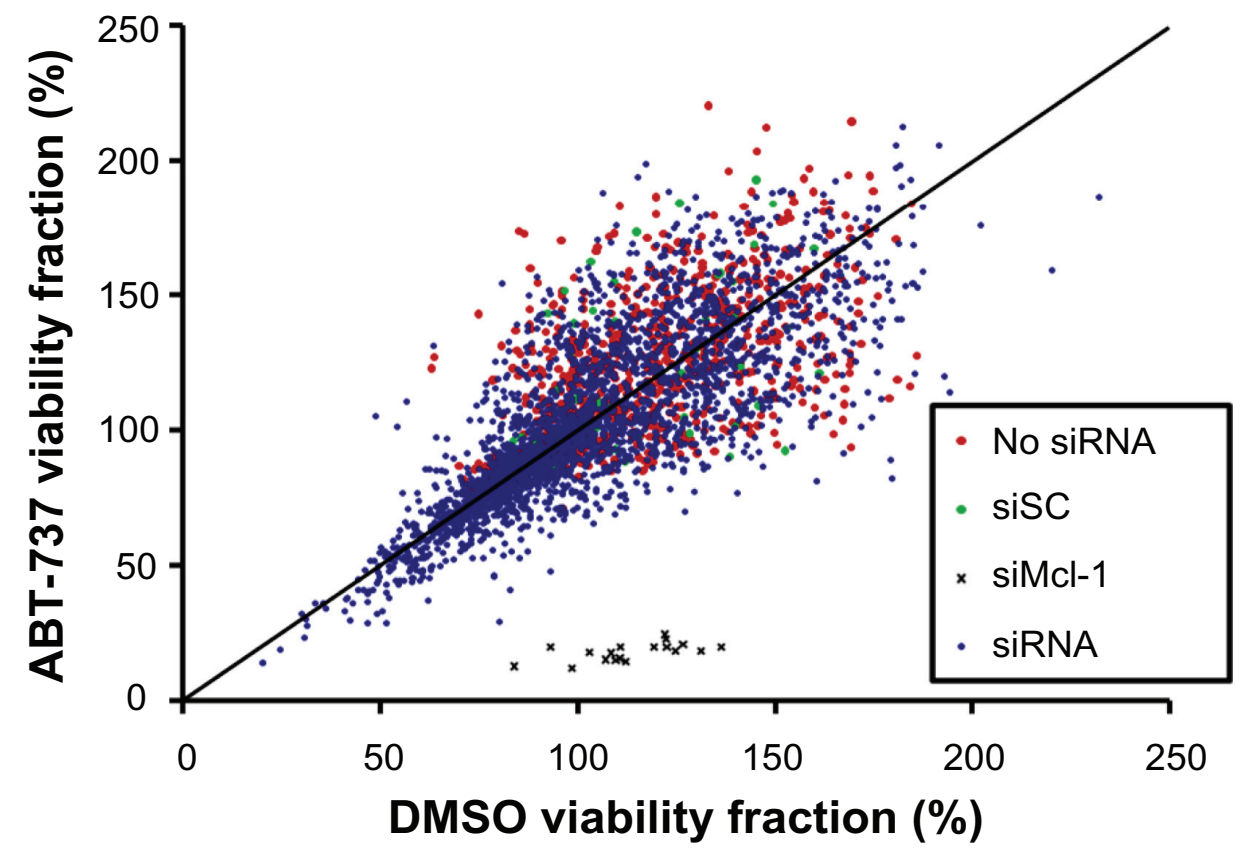

Figure 2 ABT-737-RNAi complementation screening.

HeLa cells (4000 cells/well) were reverse-transfected (using RNAiMAX) with no siRNA (negative control), scrambled control siRNA (siSC; negative control), Mcl-I siRNA (siMcl-I; positive control), or siRNAs from the kinase subset of the Ambion Silencer Human Druggable Genome siRNA Library V2 (865 genes, three siRNAs/gene) (I0 nM), and incubated for $48 \mathrm{~h}$. The cells were then treated with $0.1 \%$ DMSO or I $\mu$ M ABT-737 (dissolved in $0.1 \%$ DMSO) for $24 \mathrm{~h}$, after which cell viability was measured using ATPlite. The screen was performed twice, with mean results shown. The $y=x$ line is indicated in black.

Table I Hit siRNAs re-tested for ABT-737 complementation

\begin{tabular}{|c|c|c|c|c|}
\hline \multirow[t]{2}{*}{ Gene } & \multirow[t]{2}{*}{ siRNAI } & \multicolumn{3}{|c|}{ ABT-737/DMSO viability } \\
\hline & & SiRMA2 & siRNA3 & Average \\
\hline HAK* & 0.48 & 0.75 & 0.36 & 0.53 \\
\hline CDC42* & 0.91 & 0.96 & 0.12 & 0.66 \\
\hline PRKWNK2* & $\mathrm{I} .0 \mathrm{I}$ & 0.60 & 0.41 & 0.67 \\
\hline $\mathrm{MPP6}^{+}$ & 0.28 & 0.86 & 0.92 & 0.69 \\
\hline $\mathrm{CKMTI}^{+}$ & 1.00 & 0.31 & 0.77 & 0.69 \\
\hline $\mathrm{FGFR4}^{+}$ & 0.59 & 0.91 & 0.69 & 0.73 \\
\hline FGFR3* & 1.04 & 0.97 & 0.18 & 0.73 \\
\hline STK23+ & 0.49 & 0.80 & 0.92 & 0.74 \\
\hline $\mathrm{ADORA}^{+}$ & 0.29 & 0.97 & 0.97 & 0.74 \\
\hline STK $32 \mathrm{~A}^{+}$ & 0.45 & 0.89 & 1.05 & 0.80 \\
\hline PDPKI $^{+}$ & 0.94 & 0.57 & 0.89 & 0.80 \\
\hline FLJ $13052^{+}$ & 1.03 & 0.52 & 0.93 & 0.83 \\
\hline $\mathrm{TIFI}^{+}$ & 0.85 & 0.68 & 0.95 & 0.83 \\
\hline INSRR $^{+}$ & 0.74 & 0.76 & 1.04 & 0.85 \\
\hline $\mathrm{TXK}^{+}$ & 0.75 & 0.79 & 1.03 & 0.86 \\
\hline FLJ32685+ & 0.85 & 0.82 & 0.97 & 0.88 \\
\hline NTRKI* & 0.97 & 0.92 & 0.77 & 0.89 \\
\hline PIK4CB* & 0.60 & 1.02 & 1.06 & 0.89 \\
\hline $\mathrm{PAK}^{+}$ & 1.05 & 0.86 & 0.83 & 0.91 \\
\hline TEC* & 0.96 & 0.88 & 0.96 & 0.93 \\
\hline FER* & 1.06 & 0.87 & 0.92 & 0.95 \\
\hline STK22C* & 1.06 & 0.73 & 1.07 & 0.95 \\
\hline
\end{tabular}

Notes: *Top ten HTS hits; ${ }^{+}$additional genes selected based on HTS results and literature searches. HeLa cells were reverse transfected with $10 \mathrm{nM}$ siRNAs, incubated for $48 \mathrm{~h}$, treated with $0.1 \%$ DMSO or I $\mu$ M ABT-737 (dissolved in 0. I\% DMSO) for $24 \mathrm{~h}$, and assessed for viability using ATPlite. Ratio of ABT-737-treated cell viability to DMSO-treated cell viability is shown.

\section{Discussion}

The current study describes a cell viability-based siRNA screen for ABT-737 sensitizers. After testing for siRNA transfection/silencing efficiency and reproducibility, the 865-gene (three different siRNA sequences per gene) kinase subset of the Ambion Silencer Human Druggable Genome siRNA Library V2 was screened to test the assay. After re-assaying siRNAs from 22 genes (10 genes with the lowest average ABT-737:DMSO cell viability ratio and 12 additional genes selected based on having one siRNA with an ABT-737:DMSO cell viability ratio lower than 0.66 and literature searches), siRNAs from two confirmed "hit" genes were further evaluated.

For HAK, only one out of three siRNAs (siHAK ID\#111041) sensitized cells to ABT-737. This same siRNA was also the only one of three to decrease Mcl-1 mRNA. siMcl-1 is well-known to sensitize cells to ABT-737 (Figure 1D), ${ }^{30}$ thus off-target effects were likely responsible for the sensitization effect of this siHAK.

For WNK2, several siRNAs efficiently decreased WNK2 RNA levels and sensitized cells to ABT-737. These siRNAs did not affect Mcl-1 expression but, interestingly, they decreased HAK expression. Further studies will be required to assess whether WNK2 affects HAK, or if these siWNK2 effects are due to off-target mechanisms. 

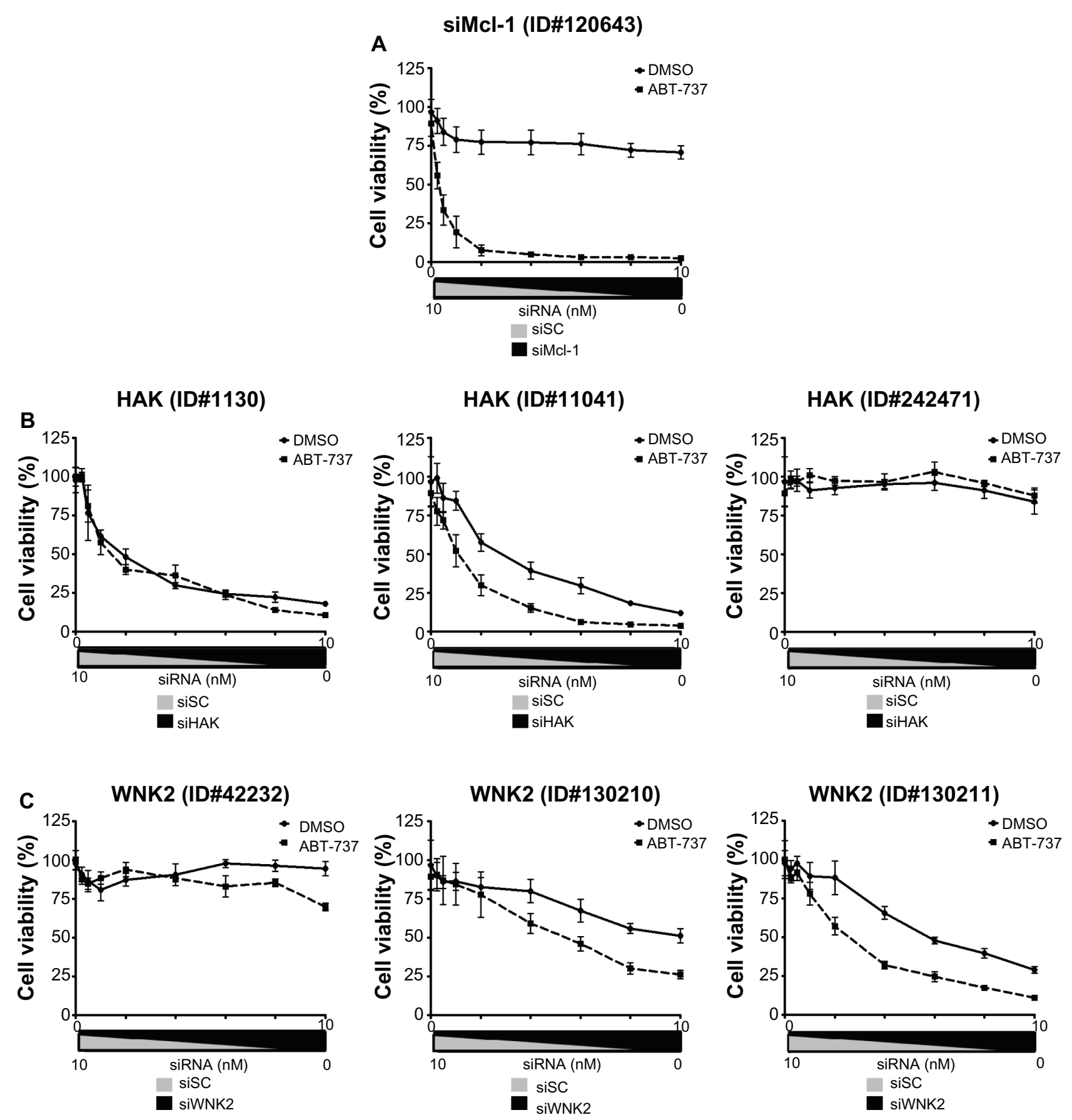

Figure 3 siRNA-mediated ABT-737 sensitization is dose-responsive. HeLa cells ( 4000 cells/well) were reverse-transfected (using RNAiMAX) with a scrambled control siRNA (siSC, negative control), a specific siRNA, or a mix of the two in varying ratios as indicated ( $10 \mathrm{nM}$ of total siRNA was transfected in each case). The cells were incubated for $48 \mathrm{~h}$ and then treated with 0.1\% DMSO or I $\mu$ M ABT-737 (dissolved in 0.1\% DMSO) for $24 \mathrm{~h}$, after which cell viability was measured using ATPlite. Mean \pm standard deviation $(n \geq 4)$ for $(\mathbf{A})$ siMcl-I (positive control), $(\mathbf{B})$ siHAK, or $(\mathbf{C})$ siWNK2 are shown (Ambion identification numbers are also indicated).

Although early reports described the exquisite sensitivity of siRNAs in silencing genes, a plethora of both sequence-related and sequence-unrelated off-target effects have been identified. ${ }^{37-39}$ Indeed, a common result of many RNAi screens and follow-up studies is not the identification of on-target screening hits, but the discovery of responsible off-target genes and mechanisms. ${ }^{40-43}$ Because of the nature of siRNAs and high-throughput studies, larger-scale screens will require more complicated statistical and biological database analyses of screening results, followed by extensive follow-up studies. ${ }^{44,45}$ Use of siRNA reagents that apply newer chemistries for reducing off-target effects may also help. ${ }^{46}$ 
Table 2 siRNA-induced changes in gene expression

\begin{tabular}{lllll}
\hline siRNA transfected & siRNA (ID\#) & \multicolumn{3}{l}{$\begin{array}{l}\text { Gene expression } \\
\text { (fold change normalized } \\
\text { to PPID) }\end{array}$} \\
\cline { 3 - 5 } & & HAK & WNK2 & Mcl-I \\
\hline Untransfected & & 1.00 & 1.00 & 1.00 \\
Mock Transfected & & 0.99 & 1.25 & 1.10 \\
siSC & & 1.38 & 1.30 & 1.38 \\
siMcl-I & 120643 & 1.50 & 0.87 & 0.10 \\
siHAK & 1130 & 0.04 & 0.94 & 1.01 \\
siHAK & $11104 \mathrm{I}$ & 0.03 & 0.80 & 0.34 \\
siHAK & $24247 \mathrm{I}$ & 0.10 & 1.42 & $1.3 \mathrm{I}$ \\
siWNK2 & 42232 & 0.45 & 0.05 & 1.00 \\
siWNK2 & 130210 & 0.67 & 0.06 & 0.99 \\
siWNK2 & $\mathrm{I} 302 \mathrm{II}$ & 0.23 & 0.15 & 1.23 \\
\hline
\end{tabular}

Notes: HeLa cells were reverse transfected with $10 \mathrm{nM}$ of the indicated siRNAs and incubated for $48 \mathrm{~h}$, after which RNA was extracted and analyzed by Q-PCR. (Note: values less than I represent a decrease in gene expression, and values greater than I represent an increase in gene expression.)

In summation, the current study describes the development and validation of an RNAi screen that identifies ABT-737 sensitizers. Future studies may use this assay for larger-scale screens and applications.

\section{Acknowledgments}

We thank Tessa Siegfried and Melanie Hanaii for assistance with manuscript preparation, as well as Dr Paul Diaz for helpful scientific discussions. This work has been supported by funds from the National Institutes of Health, P01 CA055164.

\section{Disclosure}

No conflicts of interest were declared in relation to this paper.

\section{References}

1. Green DR, Evan GI. A matter of life and death. Cancer Cell. 2002;1(1): 19-30.

2. Danial NN, Korsmeyer SJ. Cell death: critical control points. Cell. 2004;116(2):205-219.

3. Levine B. Eating oneself and uninvited guests: autophagy-related pathways in cellular defense. Cell. 2005;120(2):159-162.

4. Reed JC. Drug insight: cancer therapy strategies based on restoration of endogenous cell death mechanisms. Nat Clin Pract Oncol. 2006;3(7):388-398.

5. O'Reilly LA, Strasser A. Apoptosis and autoimmune disease. Inflamm Res. 1999;48(1):5-21.

6. Hanahan D, Weinberg RA. The hallmarks of cancer. Cell. 2000;100(1): 57-70.

7. Yip KW, Reed JC. Bcl-2 family proteins and cancer. Oncogene. 2008;27(50):6398-6406.

8. Chipuk JE, Moldoveanu T, Llambi F, Parsons MJ, Green DR. The BCL-2 family reunion. Mol Cell. 2010;37(3):299-310.

9. Youle RJ, Strasser A. The BCL-2 protein family: opposing activities that mediate cell death. Nat Rev Mol Cell Biol. 2008;9(1):47-59.

10. Bakhshi A, Jensen JP, Goldman P, et al. Cloning the chromosomal breakpoint of $\mathrm{t}(14 ; 18)$ human lymphomas: clustering around $\mathrm{JH}$ on chromosome 14 and near a transcriptional unit on 18. Cell. 1985;41(3):899-906.
11. Tsujimoto Y, Croce CM. Analysis of the structure, transcripts, and protein products of bcl-2, the gene involved in human follicular lymphoma. Proc Natl Acad Sci U SA. 1986;83(14):5214-5218.

12. Vaux DL, Cory S, Adams JM. Bcl-2 gene promotes haemopoietic cell survival and cooperates with c-myc to immortalize pre-B cells. Nature. 1988;335(6189):440-442.

13. Reed JC, Cuddy M, Slabiak T, Croce CM, Nowell PC. Oncogenic potential of bcl-2 demonstrated by gene transfer. Nature. 1988;336(6196): 259-261.

14. Beroukhim R, Mermel CH, Porter D, et al. The landscape of somatic copy-number alteration across human cancers. Nature. 2010;463(7283): 899-905.

15. Cimmino A, Calin GA, Fabbri M, et al. miR-15 and miR-16 induce apoptosis by targeting BCL2. Proc Natl Acad Sci U SA. 2005;102(39): 13944-13949.

16. Hanada M, Delia D, Aiello A, Stadtmauer E, Reed JC. bcl-2 gene hypomethylation and high-level expression in B-cell chronic lymphocytic leukemia. Blood. 1993;82(6):1820-1828.

17. Chipuk JE, Kuwana T, Bouchier-Hayes L, et al. Direct activation of Bax by p53 mediates mitochondrial membrane permeabilization and apoptosis. Science. 2004;303(5660):1010-1014.

18. Fesik SW. Insights into programmed cell death through structural biology. Cell. 2000;103(2):273-282.

19. Reed JC, Stein C, Subasinghe C, et al. Antisense-mediated inhibition of BCL2 protooncogene expression and leukemic cell growth and survival: comparisons of phosphodiester and phosphorothioate oligodeoxynucleotides. Cancer Res. 1990;50(20):6565-6570.

20. Schimmer AD, Hedley DW, Chow S, et al. The BH3 domain of BAD fused to the Antennapedia peptide induces apoptosis via its alpha helical structure and independent of Bcl-2. Cell Death Differ. 2001;8(7): 725-733.

21. Yip KW, Godoi PH, Zhai D, et al. A TR3/Nur77 peptide-based highthroughput fluorescence polarization screen for small molecule Bcl-B inhibitors. J Biomol Screen. 2008;13(7):665-673.

22. Walensky LD, Kung AL, Escher I, et al. Activation of apoptosis in vivo by a hydrocarbon-stapled BH3 helix. Science. 2004;305(5689): $1466-1470$.

23. Yip KW, Li A, Li JH, et al. Potential utility of BimS as a novel apoptotic therapeutic molecule. Mol Ther. 2004;10(3):533-544.

24. Yip KW, Mocanu JD, Au PY, et al. Combination bcl-2 antisense and radiation therapy for nasopharyngeal cancer. Clin Cancer Res. 2005; 11(22):8131-8144.

25. Leone M, Zhai D, Sareth S, Kitada S, Reed JC, Pellecchia M. Cancer prevention by tea polyphenols is linked to their direct inhibition of antiapoptotic Bcl-2-family proteins. Cancer Res. 2003;63(23): 8118-8121.

26. Oltersdorf T, Elmore SW, Shoemaker AR, et al. An inhibitor of Bcl-2 family proteins induces regression of solid tumours. Nature. 2005; 435(7042):677-681.

27. Wang JL, Liu D, Zhang ZJ, et al. Structure-based discovery of an organic compound that binds Bcl-2 protein and induces apoptosis of tumor cells. Proc Natl Acad Sci U S A. 2000;97(13):7124-7129.

28. Kitada S, Leone M, Sareth S, Zhai D, Reed JC, Pellecchia M. Discovery, characterization, and structure-activity relationships studies of proapoptotic polyphenols targeting B-cell lymphocyte/leukemia-2 proteins. J Med Chem. 2003;46(20):4259-4264.

29. Tse C, Shoemaker AR, Adickes J, et al. ABT-263: a potent and orally bioavailable Bcl-2 family inhibitor. Cancer Res. 2008;68(9): 3421-3428.

30. Konopleva M, Contractor R, Tsao T, et al. Mechanisms of apoptosis sensitivity and resistance to the $\mathrm{BH} 3$ mimetic ABT-737 in acute myeloid leukemia. Cancer Cell. 2006;10(5):375-388.

31. Hann CL, Daniel VC, Sugar EA, et al. Therapeutic efficacy of ABT-737, a selective inhibitor of BCL-2, in small cell lung cancer. Cancer Res. 2008;68(7):2321-2328.

32. High LM, Szymanska B, Wilczynska-Kalak U, et al. The Bcl-2 homology domain 3 mimetic ABT-737 targets the apoptotic machinery in acute lymphoblastic leukemia resulting in synergistic in vitro and in vivo interactions with established drugs. Mol Pharmacol. 2010;77(3):483-494. 
33. Trudel S, Stewart AK, Li Z, et al. The Bcl-2 family protein inhibitor, ABT-737, has substantial antimyeloma activity and shows synergistic effect with dexamethasone and melphalan. Clin Cancer Res. 2007; 13(2 Pt 1):621-629.

34. Yecies D, Carlson NE, Deng J, Letai A. Acquired resistance to ABT-737 in lymphoma cells that up-regulate MCL-1 and BFL-1. Blood. 2010;115(16):3304-3313.

35. Livak KJ, Schmittgen TD. Analysis of relative gene expression data using real-time quantitative PCR and the 2(-Delta Delta C(T)) method. Methods. 2001;25(4):402-408.

36. Zhang JH, Chung TD, Oldenburg KR. A simple statistical parameter for use in evaluation and validation of high throughput screening assays. J Biomol Screen. 1999;4(2):67-73.

37. Jackson AL, Linsley PS. Recognizing and avoiding siRNA off-target effects for target identification and therapeutic application. Nat Rev Drug Discov. 2010;9(1):57-67.

38. Rana TM. Illuminating the silence: understanding the structure and function of small RNAs. Nat Rev Mol Cell Biol. 2007;8(1):23-36.

39. Bartz S, Jackson AL. How will RNAi facilitate drug development? Sci STKE. 2005(295):pe39.

40. Ma Y, Creanga A, Lum L, Beachy PA. Prevalence of off-target effects in Drosophila RNA interference screens. Nature. 2006;443(7109): 359-363.
41. Lin X, Morgan-Lappe S, Huang X, et al. 'Seed' analysis of off-target siRNAs reveals an essential role of Mcl-1 in resistance to the smallmolecule Bcl-2/Bcl-XL inhibitor ABT-737. Oncogene. 2007;26(27): 3972-3979.

42. Sudbery I, Enright AJ, Fraser AG, Dunham I. Systematic analysis of off-target effects in an RNAi screen reveals microRNAs affecting sensitivity to TRAIL-induced apoptosis. BMC Genomics. 2010; 11(1):175.

43. Fedorov Y, Anderson EM, Birmingham A, et al. Off-target effects by siRNA can induce toxic phenotype. RNA. 2006;12(7):1188-1196.

44. Rines DR, Gomez-Ferreria MA, Zhou Y, et al. Whole genome functional analysis identifies novel components required for mitotic spindle integrity in human cells. Genome Biol. 2008;9(2):R44.

45. Konig R, Stertz S, Zhou Y, et al. Human host factors required for influenza virus replication. Nature. 2010;463(7282):813-817.

46. Jackson AL, Burchard J, Leake D, et al. Position-specific chemical modification of siRNAs reduces "off-target" transcript silencing. $R N A$. 2006;12(7):1197-1205.
International Journal of High Throughput Screening

\section{Publish your work in this journal}

International Journal of High Throughput Screening is an international, peer-reviewed, open access journal publishing original research, reports, editorials, reviews and commentaries dedicated to all aspects of high throughput screening, especially related to drug discovery and associated areas of biology and chemistry. The manuscript management sys-

\section{Dovepress}

tem is completely online and includes a very quick and fair peer-review system. Visit http://www.dovepress.com/testimonials.php to read real quotes from published authors.

\footnotetext{
Submit your manuscript here: http://www.dovepress.com/international-journal-of-high-throughput-screening-journal
} 